\title{
Selective activation of the probasin androgen-responsive region by steroid hormones
}

\section{S Kasper ${ }^{1}$, P S Rennie ${ }^{3}$, N Bruchovsky ${ }^{4}$, L Lin $^{5}$, H Cheng ${ }^{4}$, R Snoek ${ }^{4}$, K Dahlman-Wright ${ }^{6}$, J-A Gustafsson ${ }^{6}$, R P C Shiu ${ }^{5}$, P C Sheppard ${ }^{5}$ and R J Matusik ${ }^{2}$}

${ }^{1}$ Departments of Urologic Surgery and Cell Biology, Vanderbilt University Medical Center, A-1302 Medical Center North, Nashville, Tennessee 37232-2765, USA

${ }^{2}$ The Vanderbilt Cancer Center, Vanderbilt University Medical Center, A-1302 Medical Center North, Nashville, Tennessee 37232-2765, USA

${ }^{3}$ The Prostate Centre, The Jack Bell Research Centre, Vancouver, British Columbia, Canada V6H $3 Z 6$

${ }^{4}$ Department of Cancer Endocrinology, British Columbia Cancer Agency, Vancouver, British Columbia, Canada V5Z 4E6

${ }^{5}$ Department of Physiology, University of Manitoba, Winnipeg, Manitoba, Canada R3E 3J7

${ }^{6}$ Center for Biotechnology and Department of Medical Nutrition, NOVUM, Huddinge, Sweden

(Requests for offprints should be addressed to S Kasper, Department of Urologic Surgery, Vanderbilt University Medical Center, A-1302 MCN, 21 st at Garland Avenue, Nashville, Tennessee 37232-2765, USA)

\begin{abstract}
Glucocorticoid and androgen receptors have been shown to function through the same palindromic glucocorticoid response element (GRE) and yet have differential effects on gene transcription. In this study, we examined the functional and structural relationship of the androgen and glucocorticoid receptors with the androgen responsive region (ARR) of the probasin $(\mathrm{PB})$ gene containing two androgen receptor binding sites, ARBS-1 and ARBS-2. Transfection studies indicated that one copy of each cis-acting DNA element was essential for maximal androgen-induced chloramphenicol acetyltransferase (CAT) activity and that androgen selectivity was maintained when multiple copies of the minimal wild type (wt) androgen responsive region containing both ARBS-1 and ARBS-2 (-244 to -96) were subcloned in front of the thymidine kinase promoter. Furthermore, replacing the androgen response region with 1,2 or 3 copies of either ARBS-1 or ARBS-2 restored less than $4 \%$ of the
\end{abstract}

biological activity seen with the wt PB ARR. Multiple copies of either ARBS-1 or ARBS-2 did not result in glucocorticoid-induced CAT gene activity. By comparison, 1 or 2 copies of the tyrosine aminotransferase (TAT) GRE, as well as the mouse mammary tumour virus GRE, were strong inducers of CAT activity in response to both androgen and glucocorticoid treatment. In addition, band shift assays demonstrated that although the synthetic glucocorticoid receptor, GR-DNA binding domain (GR-DBD), and the synthetic androgen receptor, AR2, could interact with the TAT GRE (dissociation constants $K_{\mathrm{d}}$ of 63.9 and 14.1 respectively), only AR2 but not GR-DBD binding could be detected on ARBS-1 and ARBS-2. Our findings provide further evidence that androgen-induced regulation of gene transcription can occur through androgen-specific DNA binding sites that are distinct from the common GRE.

Fournal of Molecular Endocrinology (1999) 22, 313-325

\section{INTRODUCTION}

Characterization of the steroid hormone response elements of the mouse mammary tumour virus (MMTV) has shown that receptors for glucocorticoid, progesterone, mineralocorticoid and androgen can function via the same palindromic steroid response element (Ham et al. 1988). The commonality of these steroids sharing a glucocorticoid response element (GRE) consensus sequence raises the question as to how steroid-specific gene regulation is achieved. Since several steroid 
receptors bind to the GRE, sequence specificity has been largely dismissed (Freedman \& Luisi 1993, Pearce \& Yamamoto 1993). Three proposed mechanisms to explain steroid specificity in a given tissue rely upon: (a) the absolute level of the steroid receptors to stimulate (Strahle et al. 1989) or repress (Konig et al. 1992) gene expression, (b) the metabolism of selective ligands within the target cell (Edwards et al. 1988, Funder et al. 1988), and (c) the differential interaction of steroid receptors with other non-receptor transcription factors (Schule et al. 1988a,b, Strahle et al. 1988, Bruggemeier et al. 1990, Pearce \& Yamamoto 1993).

Synergistic activity or cooperativity has been defined as the greater-than-additive effect on the rate of transcription when two or more non-receptor factors are present, or when additional sites for a single activator are introduced (Dynan 1989, Frankel \& Kim 1991). Although GREs are often found in pairs, activation of transcription can occur through a single DNA element (Danesch et al. 1987, Strahle et al. 1988). In comparison, even though the androgen receptor can activate transcription through the common GRE sequence (Darbre et al. 1986, Ham et al. 1988, Roche et al. 1992), androgen-specific activation occurs when two GRElike elements are present (Adler et al. 1992, 1993, Ho et al. 1993, Rennie et al. 1993, Kasper et al. 1994). Adler et al. (1992, 1993) reported that androgen receptor (AR)-mediated activation of the Slp gene was not inherent in the two GRE binding sites but that specificity was conferred by the distance between the binding sites and by other non-receptor factors within the enhancer region. Other androgen-dependent genes, such as prostate specific antigen (Riegman et al. 1991) and C3(1) (Claessens et al. 1990, Attardi et al. 1993, Claessens et al. 1993, De Vos et al. 1993) are also activated by the binding of the androgen receptor to two GRE-like sequences.

The probasin (PB) gene, which codes for a nuclear and secreted protein of the rat dorsolateral prostate, is regulated in vivo (Dodd et al. 1983) and in vitro (Rennie et al. 1993) by androgens. The androgen-specific induction of PB gene transcription involves the participation of two different cis-acting DNA elements, androgen receptor binding site (ARBS)-1, which has sequence similarity to GRE in one half-site, and ARBS-2, which is a distinct DNA sequence (Rennie et al. 1993, Kasper et al. 1994). In transient transfection assays, glucocorticoids stimulated probasin gene transcription through these elements but they are significantly less potent than androgens (Rennie et al. 1993). Recently, the prostate-specific expression of a transgene composed of the bacterial chloram- phenicol acetyltransferase (CAT) reporter gene linked to a fragment of 5 '-flanking PB DNA containing both androgen receptor binding sites demonstrated that only androgens, not glucocorticoids, induced PB-CAT expression in vivo (Greenberg et al. 1994, Yan et al. 1997).

The present study compares the functional and structural interaction of the androgen and glucocorticoid receptors with the two androgen receptor binding sites, ARBS-1 and ARBS-2, of the PB gene (Rennie et al. 1993, Kasper et al. 1994). Transient transfection studies demonstrated that one copy of ARBS-1 and ARBS-2 was required for maximal androgen-induced CAT activity while glucocorticoids increased transcription by less than $18 \%$ of that seen with androgen treatment. Multiple copies of either ARBS-1 or ARBS-2 did not reconstitute a functional androgen-response element (ARE) or GRE since androgen- and glucocorticoid-mediated activity remained near basal levels. Furthermore, band shift and DNase I footprinting assays demonstrated that the differential behaviours of the androgen and glucocorticoid receptors are reflected in the preferential binding of the androgen receptor to ARBS-1 and ARBS-2, providing further evidence that sequences distinct from the consensus GRE can bind the androgen receptor and promote androgen-specific regulation of gene transcription.

\section{MATERIALS AND METHODS}

\section{Plasmid construction}

The construct containing -286 to +28 of the PB 5 '-flanking region, encompassing both ARBS-1 and ARBS-2, was used as the wild type (wt) in this study (Rennie et al. 1993). The construction of the plasmids containing 1,2 or 3 copies of an oligonucleotide for ARBS-1 (-244 to -217) or for ARBS-2 (-146 to -91) has been described elsewhere (Kasper et al. 1994). Additionally, 1 or 2 copies of a double-stranded oligonucleotide to the tyrosine amino transferase GRE consensus sequence GAC CCTAGAGGATCAGAACATGATGTTCTAG ATCGAATTCG were subcloned into the thymidine kinase (TK)-CAT vector (Rennie et al. 1993). The -244/-96 TK-CAT construct was generated by subcloning the PB fragment from positions -244 to -96 bp into TK-CAT. This construct contains one copy of each binding site in the wt configuration. Additionally, (ARBS-1)(ARBS-2) TK-CAT was constructed by subcloning 1 copy of the oligonucleotides for ARBS-1 and ARBS-2 into the HindIII site of the TK-CAT polylinker. Finally, the 
-244/-96 fragment was also subcloned in 1, 2 or 3 copies in front of the $\mathrm{TK}_{-81}$ luciferase (luc) gene. Nucleotide sequences were confirmed by dideoxy sequencing with Sequenase (US Biochemical, Cleveland, OH, USA). The rat androgen receptor (rAR) expression vector (Rennie et al. 1993) and the rat glucocorticoid receptor (rGR) expression vector (Miesfeld et al. 1986) used in the gene transfer experiments were previously characterized. MMTV-CAT plasmid was kindly provided by Cato et al. (1986).

For DNase I footprint experiments, a PB DNA fragment from positions -286 to +28 was ligated into the EcoRV site of the Bluescript pBS-SK+ (Stratagene, La Jolla, CA, USA) polylinker (Kasper et al. 1994). The orientation of the subcloned DNA fragment was determined by PCR sequencing (dsDNA Cycle Sequencing System, Gibco BRL, Grand Island, NY, USA).

\section{Transient transfection experiments}

Human prostatic carcinoma cells (PC-3) were plated at an initial density of $8 \times 10^{5} / 100 \mathrm{~mm}$ dish in Dulbecco's modified Eagle's media (DMEM) supplemented with $10 \%$ charcoal stripped fetal bovine serum (FBS) and transfected by the calcium phosphate method as previously described (Rennie et al. 1993). The long terminal repeat of MMTV was linked to the CAT reporter gene (MMTVCAT) as a standard to characterize both glucocorticoid- and androgen-induced gene expression. The transfection conditions were initially optimized by co-transfecting MMTV-CAT with increasing concentrations of $\mathrm{rAR}$ and rGR expression vectors driven by the SV40 promoter. Maximal MMTV-CAT activity to hormonal treatment was obtained when $5 \mu \mathrm{g} /$ plate of either SV40-driven rAR or rGR expression vectors were used (Rennie et al. 1993). Similar results were observed using the tyrosine aminotransferase (TAT) GRE. Since the fold-induction of GR/dexamethasone (DEX)induced MMTV or TAT GRE-CAT activity was routinely 2 to 3 times greater compared with that seen with AR/dihydrotestosterone (DHT), both the level of rGR gene expression and the increase in bioactivity is at least as good as, if not better, than that seen with the AR expression vector (Rennie et al. 1993). Nonetheless, levels of PB-CAT expression consistently remained greater in the presence of SV40-rAR than that observed in the presence of SV40-rGR. (Rennie et al. 1993). Thus, all CAT assays were performed using the optimal rAR and rGR concentrations for the maximal response of MMTV-CAT to DHT or DEX treatment. The cells were harvested after $24 \mathrm{~h}$ and
CAT activity was determined by the two-phase fluor diffusion assay (Nachtigal et al. 1989). The transfection assays using the androgen responsive region $(\mathrm{ARR})_{1-}^{-}, \quad(\mathrm{ARR})_{2^{-}}$, and $(\mathrm{ARR})_{3}$-TK-luc $^{-\mathrm{T}}$ constructs were carried out as described above. Luciferase activity was determined using the Promega (Madison, WI, USA) luciferase assay system (E-4531). The values plotted represent the average of at least 3 individual determinations \pm s.D.

\section{DNA probes}

Single-stranded oligonucleotides to ARBS-1, ARBS-2 or GRE were annealed to their complementary strands. The doubled-stranded DNA fragments were subsequently radiolabeled with $\left[{ }^{32} \mathrm{P}\right]$ dATP using the Klenow fragment of DNA polymerase I (Promega), purified over Nensorb 20 columns (NEN Research Products, Boston, MA, USA) and 20000 d.p.m. were added per reaction in the band shift assay (Rennie et al. 1993). Probes used in the DNase I protection assays were generated according to the method of Kasper et al. (1994).

\section{Band shift assays}

A fusion protein consisting of glutathione-Stransferase (GST) together with the DNA binding domain and hinge region of the rat androgen receptor (AR2) was expressed in E. coli and purified using glutathione affinity chromatography according to the method of Rennie et al. (1993). The GR DNA binding domain (GR-DBD) alone (containing amino acid residues Leu 420 -Ile 500 of the human GR plus an N-terminal methionine) was expressed in $E$. coli and isolated as described by Berglund et al. (1992). To determine whether the GST portion of the protein had any effects on binding, a fusion protein containing glutathione-S-transferase and the GR-DBD was expressed and purified as described (Rennie et al. 1993) and compared with the GR-DBD binding affinity on the TAT GRE. Neither the presence of GST nor the difference in molecular weight between the two receptor forms changed the binding affinity of the receptor as seen by the band shift assay. Therefore, all experiments were done using the GR-DBD. Increasing concentrations of AR2 (where $100 \mathrm{ng}=$ $2.5 \times 10^{-6} \mathrm{M}$ ) and GR-DBD (where $50 \mathrm{ng}=2.5 \times$ $\left.10^{-6} \mathrm{M}\right)$ were incubated with 20000 d.p.m. $\left[{ }^{32} \mathrm{P}\right]$ labeled fragments (described above) containing either GRE, or ARBS-1 or ARBS-2 alone. Protein-DNA complexes were separated from unbound DNA on a $5 \%$ non-denaturing polyacrylamide gel as described elsewhere (Rennie et al. 1993). 


\section{DNase I footprinting analysis}

DNase I footprinting assays were performed essentially as previously described (Kasper et al. 1994). Briefly, 10 fmoles $\left[{ }^{32} \mathrm{P}\right]$ labeled PB DNA were incubated with either affinity-purified AR2 (Rennie et al. 1993) or GR-DBD (Berglund et al. 1992) and 0.5 $\mu \mathrm{g}$ poly $[\mathrm{d}(\mathrm{I}-\mathrm{C})]$ (Pharmacia, Piscataway, NJ, USA) for 10 min on ice, digested with RQ DNase I $(500 \mathrm{mU} /$ $\mathrm{ml}$, Promega) for $75 \mathrm{~s}$ at $20{ }^{\circ} \mathrm{C}$, processed and electrophoresed on a $7 \%$ polyacrylamide/urea gel in Tris borate buffer $(50 \mathrm{mM}$ Tris $\mathrm{pH} 8 \cdot 3,50 \mathrm{mM}$ boric acid, $1 \mathrm{mM}$ EDTA) (Kasper et al. 1994). The gels were subsequently dried and exposed to BioMax film (Kodak) for autoradiography.

\section{Determination of binding affinities}

After electrophoresis, the band shift gels were dried and subjected to autoradiography. The bands corresponding to the bound protein-DNA complexes as well as the free DNA were excised and quantified by liquid scintillation counting. The data points were plotted and the GR-DBD and AR2 binding affinities $\left(K_{\mathrm{d}}\right.$ in $\left.\mathrm{nM}\right)$ were determined by non-linear regression analysis, GraphPad Prism version 1.00 (GraphPad Software Inc., San Diego, CA, USA).

\section{RESULTS}

\section{AR2 and GR-DBD recognize the same hormone response elements}

The androgen-responsive region of the $\mathrm{PB}$ gene encompasses two androgen receptor binding sites, ARBS-1 and ARBS-2, which bind the androgen receptor in a cooperative, mutually dependent manner (Kasper et al. 1994). To determine if the glucocorticoid and androgen receptors had differential effects on the transcriptional regulation of the $\mathrm{CAT}$ reporter gene containing the $\mathrm{PB}$ androgen responsive region, the induction of $\mathrm{CAT}$ activity was measured in the presence of the androgen receptor and dihydrotestosterone (DHT, $10^{-8} \mathrm{M}$ ), or the glucocorticoid receptor and dexamethasone (DEX, $\left.10^{-8} \mathrm{M}\right)$, respectively, and compared with the induction of CAT activity in the absence of hormone treatment. When both ARBS-1 and ARBS-2 were present in the wt configuration, CAT activity increased 50-fold after DHT treatment (Fig. 1A). The corresponding increase in transcription after DEX treatment was only 9 -fold or $18 \%$ of that seen with DHT, consistent with our previous report that biological activity was preferentially enhanced by androgen treatment (Rennie et al.
1993). To ascertain if differential binding of the androgen and glucocorticoid receptors could contribute to the androgen-specific response observed in the transient transfection assay, DNase I footprinting was performed with concentrations of steroid receptor ranging from 0 to $800 \mathrm{ng}$ using the 5 '-flanking region of the $\mathrm{PB}$ gene from positions -286 to +28 (Fig. 1B). In keeping with our previous observations (Kasper et al. 1994), two protected regions were observed for AR2, one over ARBS-1 $(-236$ and -223$)$ and a second over ARBS-2 (-140 and -117). A minimum of $100 \mathrm{ng}$ purified AR2 peptide was required to see a protected region over both receptor binding sites. The GR-DBD could also bind to these sites, but only at the highest concentration of GR-DBD tested (800 ng purified receptor), indicating that the binding affinity of the glucocorticoid receptor for ARBS-1 and ARBS-2 was substantially lower. However, a notable difference occurred in the binding affinities to the MMTV GREs, since as little as $100 \mathrm{ng}$ GR-DBD and at least $200 \mathrm{ng}$ AR were required for full protection of the MMTV GREs. These results are similar to those reported for MMTV since the same protection pattern was observed for both AR and GR-DBD on the MMTV long terminal repeats (Rundlett \& Miesfeld 1995). The specific androgen inducibility and the greater binding affinity of the androgen receptor, confirm the hypothesis that the 5 '-flanking region of the $\mathrm{PB}$ gene from positions -286 to +28 is an androgen responsive region.

\section{ARBS-1 and ARBS-2 preferentially function as an androgen regulated region}

The differences in androgen- and glucocorticoidinduced activity were further evaluated by placing 1,2 or 3 copies of ARBS-1, ARBS-2 or GRE in tandem and co-transfecting these constructs into PC-3 cells together with an expression vector producing the androgen (Rennie et al. 1993) or the glucocorticoid (Miesfeld et al. 1986) receptors. The MMTV-CAT plasmid served as a positive indicator for both androgen- and glucocorticoid-induced transcription. As seen in Fig. 2A, one copy of both elements in the wt configuration (-244/-96 TK$\mathrm{CAT}$ ) resulted in a 54-fold increase in CAT activity after DHT treatment. When the larger -244/-96 PB fragment was replaced by an oligonucleotide to both ARBS-1 and ARBS-2, only a 3-fold net increase in androgen-induced CAT activity was observed, suggesting that ARBS-1 and ARBS-2 alone were inadequate for full biological activity. However, the basal activity of this construct increased by $3 \cdot 6$-fold compared with that seen with the wt (-244/-96 TK-CAT), thereby quenching the androgen- 
induced activity. When either ARBS-1 or ARBS-2 was taken out of the wt configuration, and 1, 2 or 3 copies of either ARBS-1 or ARBS-2 were linked to the TK-CAT expression vector, androgen inducibility was almost abolished. In fact, full biological activity could not be achieved even with 3 copies of either ARBS-1 or ARBS-2, since androgen-induced activation of CAT gene expression increased less than 2 -fold (or $3.7 \%$ of the activity) compared with the 54-fold rise as seen when one copy of ARBS-1 and ARBS-2 was present (-244/-96 TK-CAT). These observations indicate that only one copy of each element in the wt configuration is able to elicit a full response to androgen treatment.

A

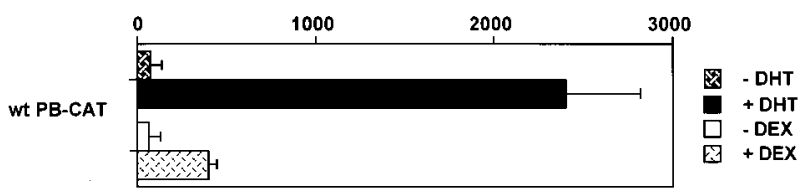

B

wt

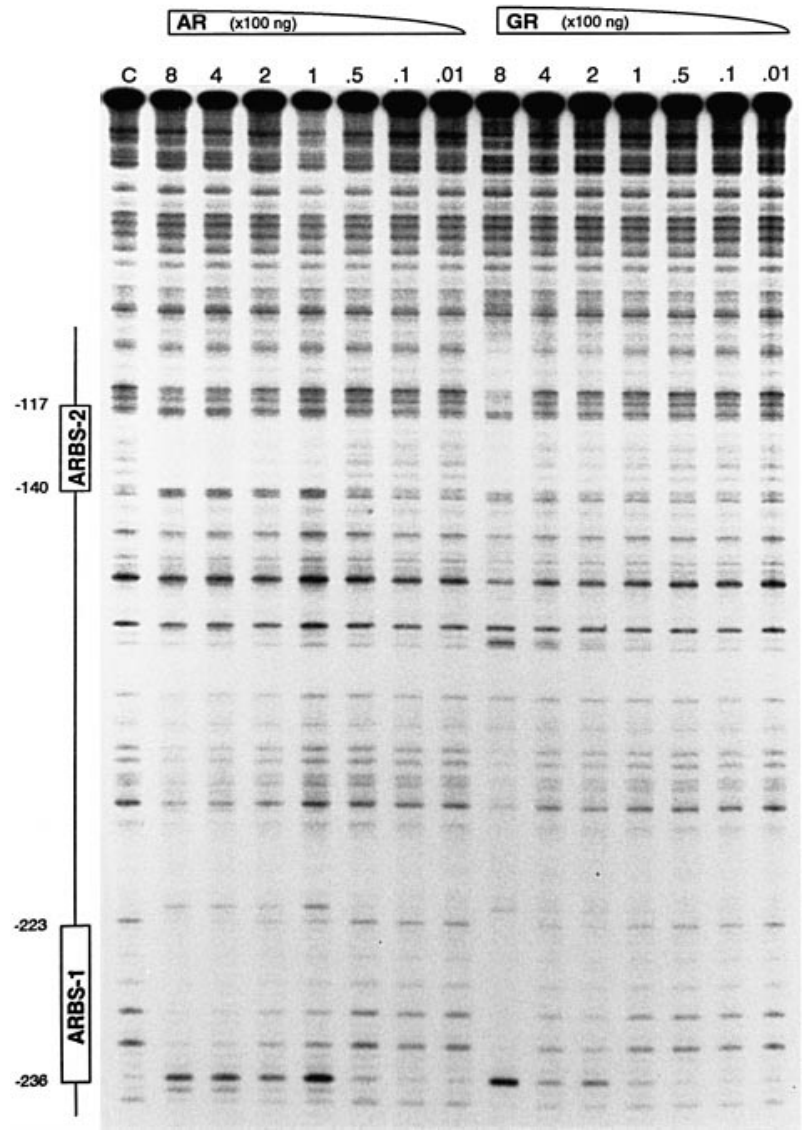

Androgen receptor specificity has been reported to involve factors other than DNA sequence (Adler et al. 1992, 1993). Subsequently, constructs containing 1 or 2 copies of either the TAT GRE or the MMTV GRE were tested to determine the effects of DHT treatment. As anticipated, androgen action could be mediated through the MMTV and TAT GRE consensus sequences (Fig. 2A) as previously reported (Rundlett \& Miesfeld. 1995). Both MMTV and TAT GRE were also strong inducers of CAT activity after DEX treatment (Fig. 2B). By comparison, when both ARBS-1 and ARBS-2 were present on the same DNA fragment (-244/-96 PB ARR), DEX-induced CAT activity was only $5 \cdot 1 \%$ of that seen with androgen treatment. In addition, increasing the copy number of either ARBS-1 or ARBS-2 (1, 2 or 3 copies) appeared to have little or no effect on glucocorticoid-mediated activation of transcription. Thus, multiple copies of either ARBS-1 or ARBS-2 could not function effectively as a GRE (Fig. 2B).

To determine the sensitivity of the androgen responsive region in the wt configuration $(-244 /-96)$ to androgen or glucocorticoid treatment, 1,2 or 3 copies of the PB ARR were subcloned in front of the TK-luc reporter gene. These constructs were co-transfected with an expression vector for the androgen receptor into $\mathrm{PC}-3$ cells and treated with androgen (R1881) or co-transfected with an expression vector for the glucocorticoid receptor and treated with glucocorticoids (DEX; Fig. 3). Treatment with $10^{-10} \mathrm{M}$ resulted in saturation levels of luciferase activity in the presence of 2 copies of

FIGURE 1. Androgen preferentially regulates $\mathrm{PB}$ gene transcription. (A) The wild-type -286/+28 PB-CAT (wt PB-CAT) was co-transfected either with an androgen receptor expression vector into $\mathrm{PC}-3$ cells and treated with $10^{-8} \mathrm{M}$ DHT or with a glucocorticoid receptor expression vector and treated with $10^{-8} \mathrm{M}$ DEX. CAT activity was measured in at least 3 determinations \pm S.D. Cross-hatched bar, basal levels in the absence of DHT; solid bar, after DHT treatment; open bar, basal levels in the absence of DEX; stippled bar, after DEX treatment. (B) Quantitative DNase I footprint analysis comparing AR2 and GR-DBD binding to DNA containing both ARBS-1 and ARBS-2. DNase I footprint analysis was performed after incubation of purified AR2 or GR-DBD (800 ng to $1 \mathrm{ng}$ ) with 10 fmoles ${ }^{32} \mathrm{P}$-labeled $5^{\prime}$-flanking PB DNA $(-286$ to +28$)$ and $0 \cdot 5 \mu \mathrm{g}$ poly[d(I-C)]. The control lane $\mathrm{C}$ is the probe digested with DNase $\mathrm{I}$ in the absence of the receptor. The protected regions ARBS-1 and ARBS-2 are shown on the left and the concentrations of AR2 and GR-DBD (indicated by AR $(\times 100 \mathrm{ng})$ and $\mathrm{GR}(\times 100 \mathrm{ng})$ respectively) are shown on the top of the figure. 

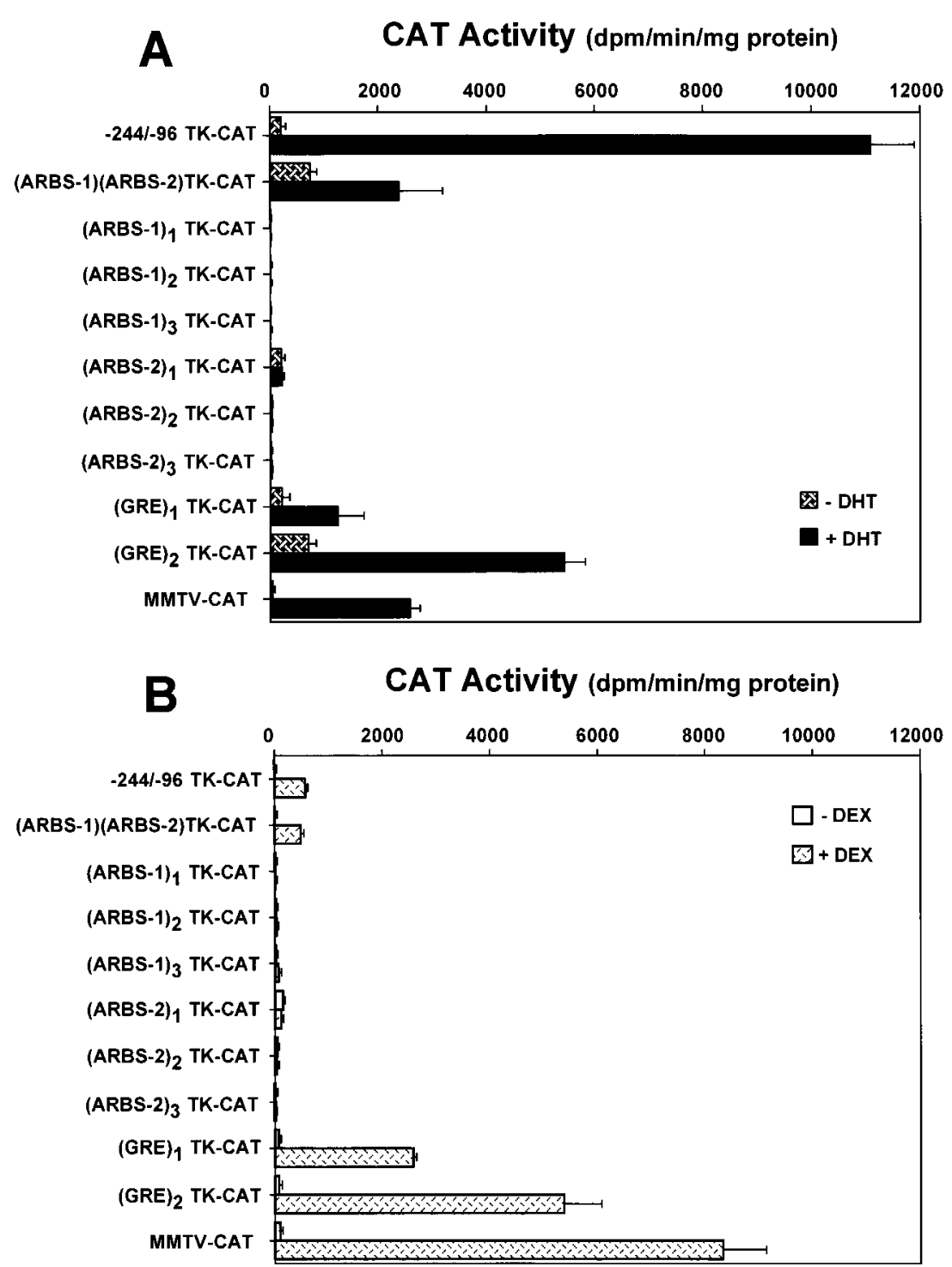

FIGURE 2. Evaluation of androgen- and glucocorticoid-induced activity on multimers of ARBS-1, ARBS-2 or TAT-GRE. Both ARBS-1 and ARBS-2 from positions -244 to -96 were subcloned into TK-CAT and served as a positive control for androgen-induced activity (-244/-96 TK-CAT). One copy of an oligonucleotide for each binding site (ARBS-1)(ARBS-2)TK-CAT and 1, 2 or 3 copies of the oligonucleotide for ARBS-1, ARBS-2 or TAT-GRE were also subcloned into TK-CAT. The MMTV-CAT construct served as a positive control for both androgen- and glucocorticoid-induced activity. These constructs were co-transfected either with an androgen receptor expression vector into PC-3 cells and treated with $10^{-8} \mathrm{M}$ DHT (A) or with a glucocorticoid receptor expression vector and treated with $10^{-8}$ M DEX (B). Values were plotted as described previously.

ARR (172-fold) and activity increased 251-fold using 3 copies of ARR. The corresponding levels of DEX-induced activity were 5 -fold for 2 copies of ARR and 15-fold for 3 copies of ARR at this concentration. Therefore, at saturation levels of the steroid hormone $\left(10^{-10} \mathrm{M}\right)$, luciferase gene activity after DEX treatment for 2 and 3 copies of ARR was $3 \%$ and $6 \%$ of that seen with androgen treatment 


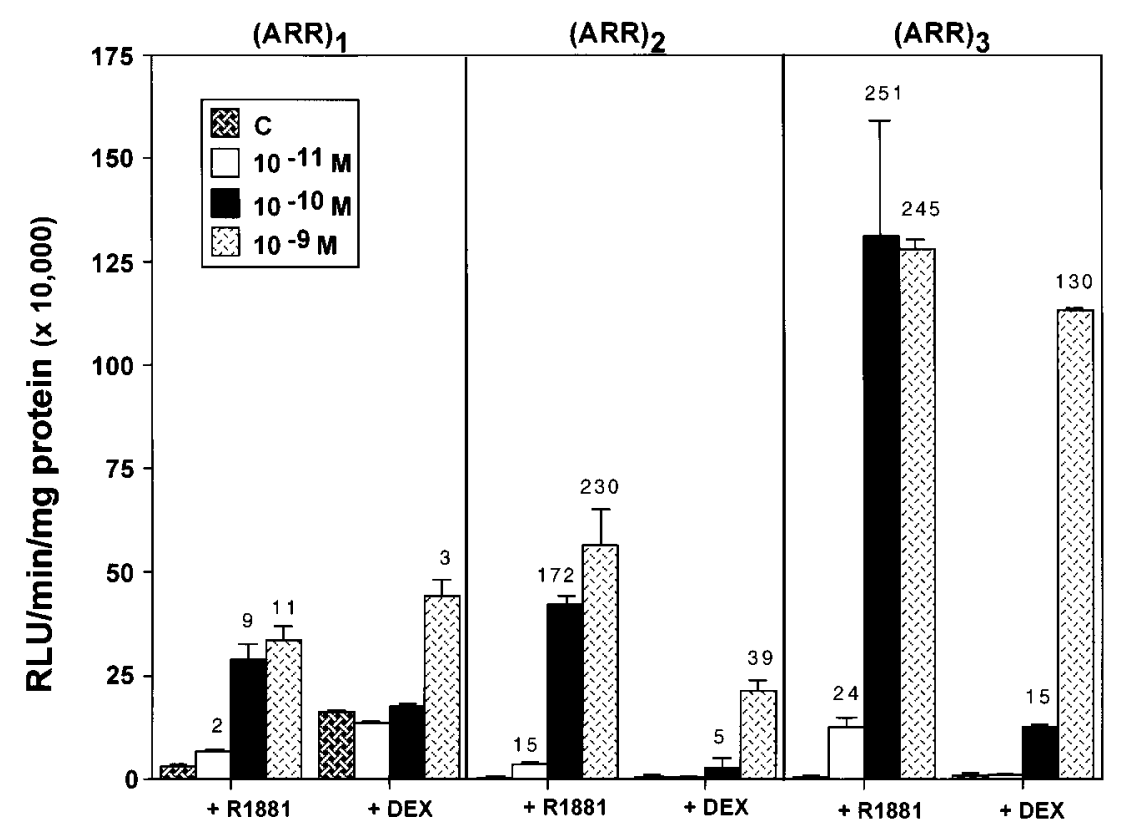

FIGURE 3. Androgen and glucocorticoid activity on multimers of the minimal wt probasin ARR. Constructs containing 1, 2 or 3 copies of the wt PB ARR ( $-244 \mathrm{bp}$ to $-96 \mathrm{bp}$ ) linked to TK-CAT were labeled $(\mathrm{ARR})_{1},(\mathrm{ARR})_{2}$ and $(\mathrm{ARR})_{3}$ respectively. These constructs were co-transfected either with an androgen receptor expression vector into PC-3 cells and treated with $10^{-11} \mathrm{M}$, $10^{-10} \mathrm{M}$ or $10^{-9} \mathrm{M}$ R1881 or with a glucocorticoid receptor expression vector and treated with $10^{-11} \mathrm{M}, 10^{-10} \mathrm{M}$ or $10^{-9} \mathrm{M}$ DEX. The fold-induction in response to hormone treatment was determined by comparing reporter gene activity induced by R1881 or by DEX to the corresponding baseline values in the absence of hormone $(\mathrm{C})$ and is represented by the numbers above the histogram bars. Activity and fold-induction were measured in at least 3 determinations \pm s.D. RLU, relative light units.

respectively. This indicates that the probasin ARR was preferentially regulated by androgens.

\section{Relative binding affinities of GRE, ARBS-1 and ARBS-2 for the androgen and glucocorticoid receptors}

The relative DNA binding affinities of AR2 and GR-DBD were determined in the standard band shift assay using increasing concentrations of receptor and a fixed amount of a doubled-stranded radiolabeled oligonucleotide to ARBS-1, ARBS-2 or GRE (Fig. 4 ). As expected, the monomeric, as well as the dimeric, complexes of GR-DBD/GRE were observed with as little as $6 \cdot 25 \mathrm{ng}$ purified receptor (Fig. 4A). The AR2-GRE complex was also evident at $6 \cdot 25 \mathrm{ng}$ AR2, although AR2 did not appear to have the ability to form a monomer complex analogous to that reported for the MMTV GREs (Rundlett \& Miesfeld 1995). Surprisingly, GR-DBD showed little or no binding at ARBS-1
(Fig. 4B) and minimal binding at the highest receptor concentration (200 ng purified receptor) to ARBS-2 (Fig. 4C). To eliminate any effects that may be attributed to GST, a GST-GR-DBD fusion protein (GR2) was compared with the GR-DBD that was used in all the binding studies (Fig. 5). The binding affinities of GST-GR and GR2 to the TAT GRE were comparable at all concentrations tested, implying that the GST fusion protein did not impede protein-DNA complex formation.

The dissociation constants $\left(K_{\mathrm{d}}\right)$ for GR-DBD and AR2 binding of TAT GRE were calculated by excising the protein-DNA complexes from the gels, quantifying the bound counts by liquid scintillation counting and determining $K_{\mathrm{d}}$ by non-linear regression analysis (GraphPad Prism version 1.00, GraphPad Software Inc.). The resulting binding curves $\left(K_{\mathrm{d}}\right)$ are summarized in Fig. 6C. The $K_{\mathrm{d}}$ value of $63.9 \mathrm{nM}$ for GR-DBD binding of TAT GRE is comparable to the previously reported value of $62 \mathrm{nM}$ (Rundlett \& Miesfeld 1995). As indicated 


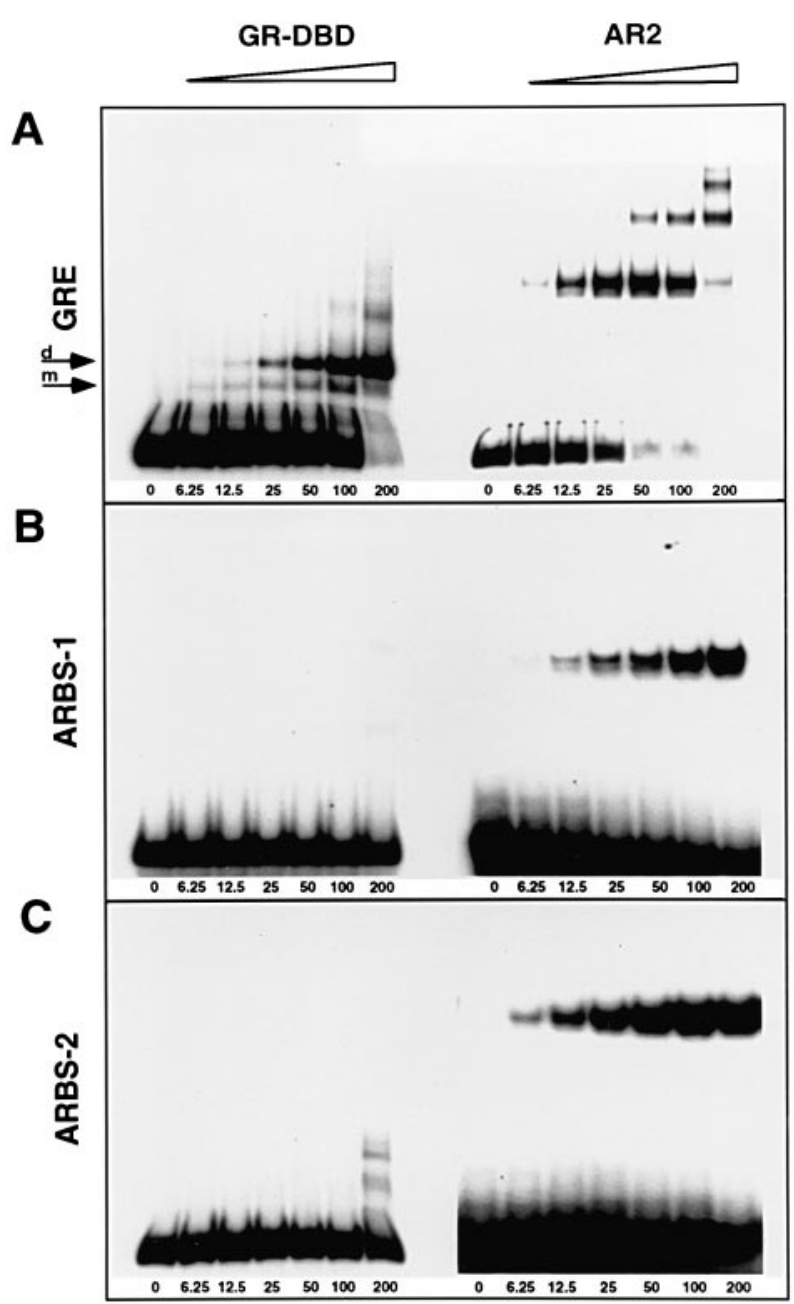

FIGURE 4. DNA binding specificity of AR2 and GST-GR to ARBS-1 and ARBS-2 and TAT-GRE. Double-stranded, ${ }^{32} \mathrm{P}$-labeled oligonucleotides to TAT-GRE, ARBS-1 or ARBS-2 were incubated with increasing concentrations of purified AR2 or GST-GR and evaluated in the band shift assay. The amounts of GR-DBD and AR2 added to the binding reaction are shown below each lane $(6 \cdot 25$ to $200 \mathrm{ng})$. (A) GR-DBD and AR2 binding to ${ }^{32} \mathrm{P}$-labeled TAT-GRE;

(B) GR-DBD and AR2 binding to ${ }^{32} \mathrm{P}$-labeled ARBS-1; (C) GR-DBD and AR2 binding to ${ }^{32} \mathrm{P}$-labeled ARBS-2. $\mathrm{d}$, dimer; m, monomer

by the band shift assay (Fig. 4), DNA binding affinities could not be determined for GR-DBD binding of ARBS-1 and ARBS-2. In contrast, the binding of AR2 to TAT GRE $\left(K_{\mathrm{d}}=14 \cdot 1 \mathrm{nM}\right)$ was more efficient than that for ARBS-1 $\left(K_{\mathrm{d}}=20 \mathrm{nM}\right)$, but less efficient than that observed for the high affinity site, ARBS-2 $\left(K_{\mathrm{d}}=6 \cdot 7 \mathrm{nM}\right)$ (Kasper et al. 1994). Both the ability of AR2 to bind TAT GRE, and the negligible binding of GR-DBD to ARBS-1 and ARBS-2, are reflected in the functional study (Fig. 3), suggesting that although both receptors can activate transcription through the TAT GRE, androgen-specific regulation occurs through ARBS-1 and ARBS-2.

\section{DISCUSSION}

In this study, we have further characterized the relationship between ARBS-1 and ARBS-2 by determining their functional activity in response to androgen and glucocorticoid treatment and by linking this activity to the binding kinetics for the androgen and glucocorticoid receptors. A wellestablished pattern of steroid hormone regulation is that one GRE and a TATA box are sufficient for steroid induction (Ham et al. 1988, Schule et al. 1988a) and that two GR binding sites result in a synergistic or cooperative increase of transcription in response to glucocorticoids (Schule et al. 1988a), progesterones (Chalepakis et al. 1988) or androgens (Ham et al. 1988).

In a previous study, the elements initially called ARE-1 and ARE-2 (Rennie et al. 1993) were renamed androgen receptor binding sites, ARBS-1 and ARBS-2 respectively (Kasper et al. 1994). This conclusion was based on the observations that neither element alone could function as a response element and that a single point mutation in either site prevented the androgen receptor from binding (Kasper et al. 1994), eliminating androgen-induced biological activity by $97 \%$ (Rennie et al. 1993). Yet, when the DNA fragment contained both ARBS-1 and ARBS-2 in the wt configuration, a 50-fold increase in CAT activity was measured. The ARBS-1 and ARBS-2, together with the surrounding wt sequences, were required for the probasin androgen responsive region (ARR).

In this study, we determined if multiple copies of either ARBS-1 or ARBS-2 could function as a steroid response element. Surprisingly, this could not be done. Even with 3 copies of either element, the ARR could not be reconstituted. Three copies of ARBS-2 conferred only a 2-fold increase in CAT activity in response to androgen treatment, whereas a 54-fold rise in CAT activity was observed with the wt ARR (Fig. 2). A functional GRE could not be generated by placing either ARBS-1 or ARBS-2 in tandem compared with that seen with the TAT GRE or the MMTV GRE (Fig. 2). However, a single copy of ARBS-1 adjacent to ARBS-2 ((ARBS-1)(ARBS-2)TK-CAT) resulted in the same level of CAT activity as the $-244 /-96$ TK-CAT construct (Fig. 2B). This suggests that although the flanking sequences were required for 

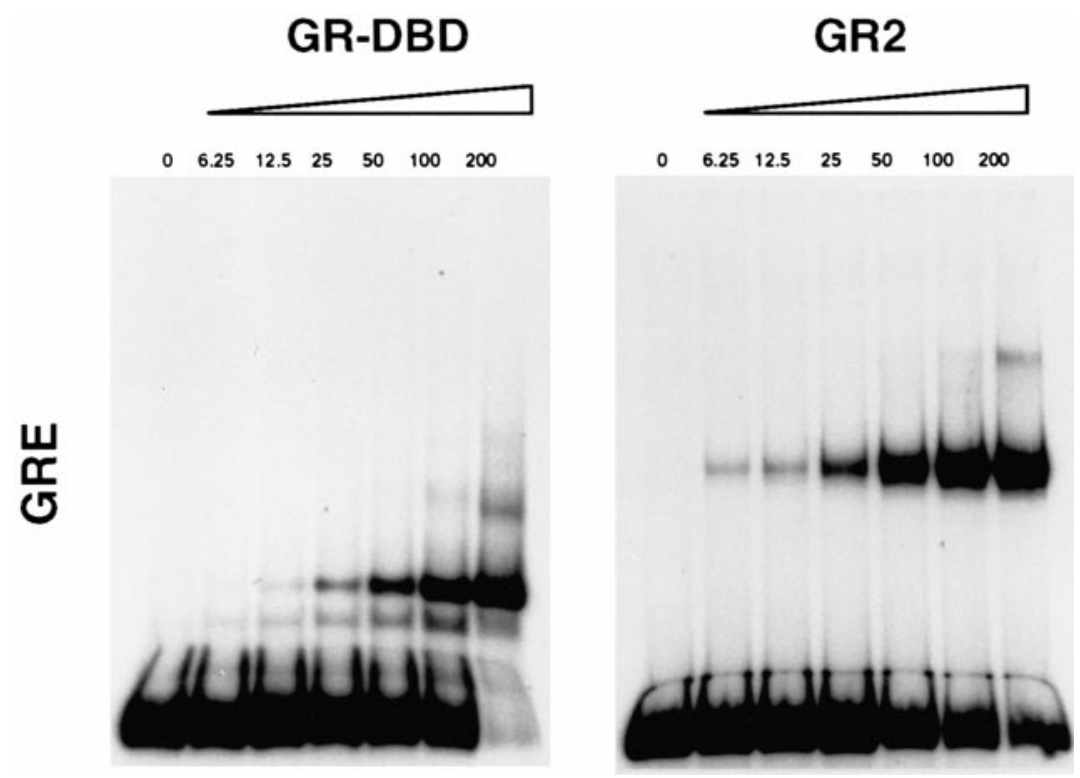

FIGURE 5. Comparison of GR-DBD and GR2 binding to TAT-GRE. (A) GST-GR-DBD fusion protein (GR2) was made as described in the Materials and Methods section and GR2 binding was compared with GR-DBD binding in the band shift assay. The amount of receptor added to each binding reaction is indicated above the lanes $(6 \cdot 25$ to $200 \mathrm{ng})$.

maximal activity, the two ARBS elements combined were sufficient for steroid induction. Thus, it appears that: (a) individually, neither ARBS-1 nor ARBS-2 function as an ARE or a GRE, (b) one copy of each ARBS-1 and ARBS-2 within the ARR is essential for full biological activity, (c) multiple copies of either element do not generate a functional ARE or GRE and (d) the endogenous probasin ARR with one copy of ARBS-1 and ARBS-2 in the wt configuration is the essential unit required for androgen-specific regulation of $\mathrm{PB}$ gene transcription.

The level of bioactivity appears to correlate with the ability of the receptor to bind to ARBS-1 and ARBS-2. As seen in Fig. 4, GR-DBD binding of ARBS-1 and ARBS-2 was negligible, whereas the binding affinities of AR2 to ARBS-1 and ARBS-2 were $K_{\mathrm{d}}=20 \mathrm{nM}$ and $K_{\mathrm{d}}=6.7 \mathrm{nM}$ respectively (Fig. 6C). The loss of GR-DBD binding was unexpected since ARBS-1 is GRE-like, having sequence similarity to one half-site of the GRE consensus sequence, a steroid hormone response element which functions as effectively for androgen- (Denison et al. 1989, Riegman et al. 1991, Adler et al. 1992, Roche et al. 1992, Claessens et al. 1993) as it does for glucocorticoid- (Tsai et al. 1988), progesterone- (Chalepakis et al. 1988, Tsai et al. 1989), and mineralocorticoid (Pearce \&
Yamamoto 1993) -induced regulation of gene transcription.

Whether using truncated receptor proteins exactly mimics the binding of AR and GR to ARBS-1 and ARBS-2 is not known. However, in an elegant study Kallio and colleagues (1994) have analyzed the androgen receptor-DNA interactions with a number of different AR proteins showing that full-length AR interacted with a TAT-ARE with only a $2 \cdot 6$-fold higher affinity than with a truncated 46-408 AR. They reported that the rates of dissociation curves for both receptors were nearly identical, both AR proteins recognized the same bases, and both AR proteins formed not only homodimers but also had the ability to form heterodimers in the band shift assay using the $\mathrm{C} 3(1)$ ARE (Kallio et al. 1994). However, they did not detect monomeric AR/DNA complexes similar to those seen in GR/GRE complexes. In contrast, the GR-DBD could form both monomeric and dimeric complexes with the GRE (Hard et al. 1990, Rundlett \& Miesfeld 1995). Thus, the N-terminal of the AR appeared to influence receptor/DNA interaction only to a moderate extent.

Claessens et al. (1996), in comparing the C(3)ARE with ARBS-2 of the probasin gene found that replacing the $\mathrm{C}(3) \mathrm{ARE}$ with an oligonucleotide to ARBS-2 switched the regulation of CAT gene 
A

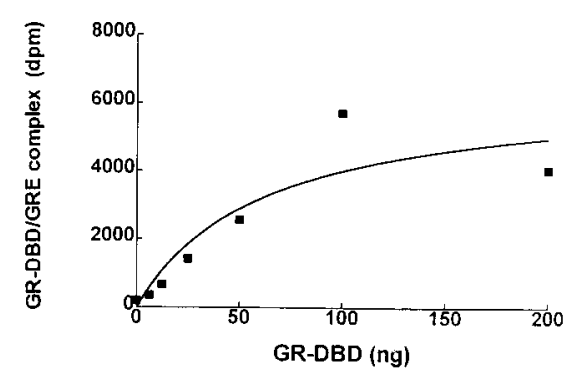

B

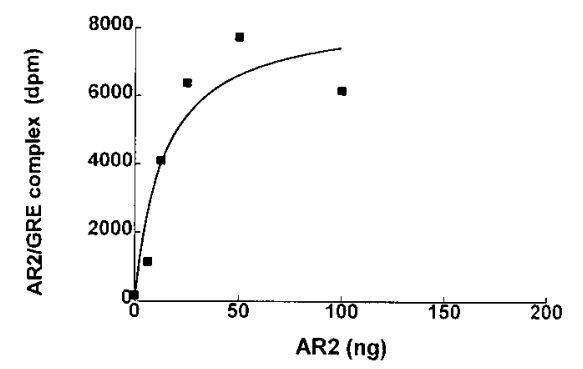

C

Comparison of AR2 and GR-DBD binding affinities.

\begin{tabular}{|c|cc|}
\hline & AR2 & GR-DBD \\
& $K_{d}(n M)$ & $K_{d}(n M)$ \\
\hline ARBS-1* $^{*}$ & 20.0 & - \\
ARBS-2* $^{*}$ & 6.7 & - \\
TAT-GRE & 14.1 & 63.9 \\
\hline
\end{tabular}

FIGURE 6. Relative binding affinities of GR-DBD and AR2 for the TAT-GRE oligonucleotide. The amount of protein-DNA complex formed was estimated by excising the bands from the band shift assay as previously described, and directly counting their radioactivity. The resulting $K_{\mathrm{d}}$ was determined by non-linear regression analysis. (A) GR-DBD binding to TAT-GRE. (B) AR2 binding to TAT-GRE. (C) Comparison of AR2 and GR-DBD binding affinities; * the $K_{\mathrm{d}}$ values for AR2 binding to ARBS-1 and ARBS-2 were taken from Kasper et al. (1994).

expression from glucocorticoid- to androgenspecific induction, suggesting that the specificity of androgen action lay within the ARBS-2 sequence itself. To extend these results to normal prostatic epithelial cells in vivo, the $\mathrm{PB}$ 5'-flanking region ( -426 to +28 bp containing ARBS-1 and ARBS-2) was linked to the CAT gene and used to generate transgenic mice (Greenberg et al. 1994). Castration of these mice resulted in a marked decrease in -426 PB-CAT gene expression, which could be restored to pre-castration levels by androgen treatment. Remarkably, glucocorticoid treatment had no effect on -426 PB-CAT transgene transcription with the stable integration of the transgene in transgenic animals (Greenberg et al. 1994). The same results were obtained in transgenic mice generated with a transgene containing a large $12000 \mathrm{bp}$ fragment of the PB 5'-flanking sequence linked to the CAT reporter gene (LPB-CAT) (Yan et al. 1997). Furthermore, probasin transgene expression rose dramatically in concert with increasing androgen levels during sexual maturation in both the -426 PB-CAT and the LPB-CAT transgenic mouse models (Greenberg et al. 1994, Yan et al. 1997). Thus, the experiments in transgenic animals confirm that the in vivo regulation of the probasin gene transcription is androgen-specific and is dictated by the ARR of the probasin gene.

The mechanism of glucocorticoid-induced PB gene transcription in vitro is uncertain. Limited activation of CAT transcription in response to glucocorticoid treatment, and some protection of ARBS-1 and ARBS-2 by the glucocorticoid receptor were observed when both elements were present on the same fragment in the wt configuration (Fig. 1). Also, the sensitivity of one copy of the wt ARR to androgen was at least two orders of magnitude greater than that to glucocorticoid, since little to no activity was observed in the glucocorticoid-treated group in the presence of low concentrations of hormone (Fig. 3). A rise in DEX-induced reporter gene activity was finally detected with 3 copies of the wt PB ARR at the highest level of hormone tested, although this was still $50 \%$ of that seen with androgen. Therefore, it is likely that at very high concentrations of glucocorticoids, transcription is activated by the binding of the glucocorticoid receptor to ARBS-1 and ARBS-2.

Alternatively, induction of probasin gene transcription by glucocorticoids could be due to a secondary response. Accumulation of a steroidregulated primary gene product would then be necessary before the secondary response could be activated (Hess et al. 1990, Urness \& Thummel 1990). Castration experiments show that an increase in endogenous rat probasin mRNA levels can be induced by glucocorticoid treatment, although the induction is only $67 \%$ that of the intact PB mRNA levels (Matusik et al. 1991). This observation could not be repeated in the transgenic mouse model containing up to $12000 \mathrm{bp}$ of the PB 5'-flanking region (Yan et al. 1997), suggesting that there may be a GRE or secondary response element located elsewhere in the PB genomic structure.

Recently Juang et al. (1995) reported that androgen-induced, mitochondrial aspartate aminotransferase gene transcription in the rat prostate is regulated by two androgen response regions, one of which has a similar sequence to ARBS-2. Dai and Bernstein (1996) reported that androgen regulation 
functions synergistically via two ARE sequences located in the AR coding region. One of these sites has sequence similarity with the PB ARBS2 sequence (Dai \& Burnstein 1996). Thus, androgen specificity in other genes may be conferred by two AREs if one sequence is similar to the PB ARBS-2 sequence (Juang et al. 1995, Dai \& Burnstein 1996) and glucocorticoid hormone regulation of a gene can be altered to androgen specificity with the addition of the ARBS2 sequence (Claessens et al. 1996).

Other mechanisms to explain specificity of hormone action, in addition to receptor affinity, may involve the tertiary structure of the DNA sequences adjacent to the receptor binding sites. Recent reports have shown that the tertiary configuration of DNA adjacent to the GRE (Dahlman Wright et al. 1992) or the resultant changes in tertiary structure after receptor binding (Leidig et al. 1992, Nardulli et al. 1993) can regulate glucocorticoid-induced transcription (Bracco et al. 1989, Lue et al. 1989, Rojo \& Salas 1991). A further mechanism involves the interaction of steroid hormones with other transcription factors (Baniahmad \& Tsai 1993, Freedman \& Luisi 1993, Truss \& Beato 1993). For example, progesterone response elements and GREs are often found clustered with binding sites for transcription factors such as nuclear factor (NF)-1 (Bruggemeier et al. 1990), Sp1 (Strahle et al. 1988), the CCAAT box binding factor (Schule et al. 1988a, Strahle et al. 1988) and/or AP-1 (Diamond et al. 1990, Schule et al. 1990, Yang-Yen et al. 1990, Pearce \& Yamamoto 1993), which facilitate steroid receptor action in a cooperative manner. Kallio and colleagues (1996) reported that both AR and AP-1 proteins can act synergistically in regulating gene transcription. Thus, the presence of AP-1 like sequences at the 3' end of both ARBS-1 and ARBS- 2 suggests that AP- 1 may play a role in the regulation of the probasin gene. When the intervening nucleotides are removed and ARBS-1 and ARBS-2 are juxtaposed, bioactivity drops from 50 - to 3 -fold suggesting that spatially, the intervening nucleotides are important for function. It is possible that the intervening nucleotides contain DNA elements for transcription factors that facilitate the binding of the androgen receptor to ARBS-1 and -2, thereby modulating androgeninduced transcription. Clearly, many factors act in concert to determine the rate and magnitude of the androgen-induced regulation of PB gene expression.

In conclusion, androgen-specific regulation of the PB gene involves a complex interplay of many factors which include specific interaction of the androgen receptor with ARBS-1 and ARBS-2. Thus, ARBS-1 and ARBS-2 are distinct from the consensus GRE since these elements preferentially bind the androgen receptor and specifically activate androgen-induced gene transcription. Our findings provide further evidence that androgen-induced regulation of gene transcription can occur through androgen-specific DNA response elements sequences.

\section{ACKNOWLEDGEMENTS}

This work is supported in part by grants from the Association for the Cure of Prostate Cancer ( $\mathrm{CaP}$ CURE), Manitoba Health Research Council, Medical Research Council of Canada, Swedish Medical Research Council (Wo.13X-2819), the Frances Williams Preston Laboratories of the T J Martell Foundation, the J Davis Foundation and the Ingram Charitable Fund.

\section{REFERENCES}

Adler AJ, Danielsen M \& Robins DM 1992 Androgen-specific gene activation via a consensus glucocorticoid response element is determined by interaction with nonreceptor factors. Proceedings of the National Academy of Sciences of the USA 89 11660-11663.

Adler AJ, Scheller A \& Robins DM 1993 The stringency and magnitude of androgen-specific gene activation is a combinatorial function of receptor and nonreceptor binding site sequences. Molecular and Cellular Biology 13 6326-6335.

Attardi LD, Von Seggern D \& Tjian R 1993 Ectopic expression of wild-type or a dominant-negative mutant of transcription factor NTF-1 disrupts normal Drosophila development. Proceedings of the National Academy of Sciences of the USA 90 10563-10567.

Baniahmad A \& Tsai MJ 1993 Mechanisms of transcriptional activation by steroid hormone receptors. Fournal of Cellular Biochemistry 51 151-156.

Berglund H, Kovacs H, Dahlman Wright K, Gustafsson JA \& Hard T 1992 Backbone dynamics of the glucocorticoid receptor DNA-binding domain [published erratum appears in Biochemistry 199332 3829]. Biochemistry 31 12001-12011.

Bracco L, Kotlarz D, Kolb A, Diekmann S \& Buc H 1989 Synthetic curved DNA sequences can act as transcriptional activator in Escherichia coli. EMBO Fournal 8 4289-4296.

Bruggemeier U, Rogge L, Winnacker EL \& Beato M 1990 Nuclear factor I acts as a transcription factor on the MMTV promoter but competes with steroid hormone receptors for DNA binding. EMBO fournal 9 2233-2239.

Cato AC, Miksicek R, Schutz G, Arnemann J \& Beato M 1986 The hormone regulatory element of mouse mammary tumour virus mediates progesterone induction. EMBO Fournal 5 2237-2240.

Chalepakis G, Arnemann J, Slater E, Bruller HJ, Gross B \& Beato M 1988 Differential gene activation by glucocorticoids and progestins through the hormone regulatory element of mouse mammary tumor virus. Cell 53 371-382.

Claessens F, Rushmere NK, Davies P, Celis L, Peeters B \& Rombauts WA 1990 Sequence-specific binding of androgenreceptor complexes to prostatic binding protein genes. Molecular and Cellular Endocrinology 74 203-212. 
Claessens F, Celis L, De Vos P, Peeters B, Heyns W, Verhoeven G \& Rombauts W 1993 Intronic androgen response elements of prostatic binding protein genes. Biochemical and Biophysical Research Communications 191 688-694.

Claessens F, Alen P, Devos A, Peeters B, Verhoeven G \& Rombauts W 1996 The androgen-specific probasin response element 2 interacts differentially with androgen and glucocorticoid receptors. Fournal of Biological Chemistry 271 19013-19016.

Dahlman Wright K, Wright AP \& Gustafsson JA 1992 Determinants of high-affinity DNA binding by the glucocorticoid receptor: evaluation of receptor domains outside the DNA-binding domain. Biochemistry 31 9040-9044.

Dai JL \& Burnstein KL 1996 Two androgen response elements in the androgen receptor coding region are required for cell specific up-regulation of receptor messenger RNA. Molecular Endocrinology 10 1582-1594.

Danesch U, Gloss B, Schmid W, Schutz G, Schule R \& Renkawitz R 1987 Glucocorticoid induction of the rat tryptophan oxygenase gene is mediated by two widely separated glucocorticoid-responsive elements. EMBO Fournal 6 625-630.

Darbre P, Page M \& King RJB 1986 Androgen regulation by the long terminal repeat of mouse mammary tumour virus. Molecular and Cellular Biochemistry 6 2847-2854.

De Vos P, Claessens F, Peeters B, Rombauts W, Heyns W \& Verhoeven G 1993 Interaction of androgen and glucocorticoid receptor DNA-binding domains with their response elements. Molecular and Cellular Endocrinology 90 R11-R16.

Denison SH, Sands A \& Tindall DJ 1989 A tyrosine aminotransferase glucocorticoid response element also mediates androgen enhancement of gene expression. Endocrinology 124 1091-1093.

Diamond MI, Miner JN, Yoshinaga SK \& Yamamoto KR 1990 Transcription factor interactions: selectors of positive or negative regulation from a single DNA element. Science 249 1266-1272.

Dodd JG, Sheppard PC \& Matusik RJ 1983 Characterization and cloning of rat dorsal prostate mRNAs. Androgen regulation of two closely related abundant mRNAs. Fournal of Biological Chemistry 258 10731-10737.

Dynan WS 1989 Modularity in promoters and enhancers. Cell 58 1-4.

Edwards CR, Stewart PM, Burt D, Brett L, McIntyre MA, Sutanto WS, de Kloet ER \& Monder C 1988 Localisation of 11 beta-hydroxysteroid dehydrogenase-tissue specific protector of the mineralocorticoid receptor. Lancet 2 986-989.

Frankel AD \& Kim PS 1991 Molecular structure of transcription factors: implications of gene regulation. Cell $\mathbf{6 5}$ 717-719.

Freedman LP \& Luisi BF 1993 On the mechanism of DNA binding by nuclear hormone receptors: a structural and functional perspective. Fournal of Cellular Biochemistry $\mathbf{5 1}$ $140-150$.

Funder JW, Pearce PT, Smith R \& Smith AI 1988 Mineralocorticoid action: target tissue specificity is enzyme, not receptor, mediated. Science 242 583-585.

Greenberg NM, DeMayo FJ, Sheppard PC, Barrios R, Lebovitz M, Finegold M, Angelopoulou R, Dodd JG, Duckworth ML, Rosen JM \& Matusik RJ 1994 The rat probasin gene promoter directs hormonally and developmentally regulated expression of a heterologous gene specifically to the prostate in transgenic mice. Molecular Endocrinology 8 230-239.
Ham J, Thomson A, Needham M, Webb P \& Parker M 1988 Characterization of response elements for androgens, glucocorticoids and progestins in mouse mammary tumour virus. Nucleic Acids Research 16 5263-5276.

Hard T, Kellenbach E, Boelens R, Maler BA, Dahlman K, Freedman LP, Carlstedt-Duke J, Yamamoto KR, Gustafsson JA \& Kaptein R 1990 Solution structure of the glucocorticoid receptor DNA-binding domain. Science 249 $157-160$.

Hess P, Meenakshi T, Chan GC, Carlstedt Duke J, Gustafsson JA \& Payvar F 1990 Purified glucocorticoid receptors bind selectively in vitro to a cloned DNA fragment that mediates a delayed secondary response to glucocorticoids in vivo. Proceedings of the National Academy of Sciences of the USA 87 2564-2568.

Ho KC, Marschke KB, Tan J, Power SG, Wilson EM \& French FS 1993 A complex response element in intron 1 of the androgen-regulated $20-\mathrm{kDa}$ protein gene displays cell type-dependent androgen receptor specificity. Fournal of Biological Chemistry 268 27226-27235.

Juang HH, Costello LC \& Franklin RB 1995 Androgen modulation of multiple transcription start sites of the mitochondrial aspartate aminotransferase gene in rat prostate. Fournal of Biological Chemistry 270 12629-12634.

Kallio PJ, Palvimo JJ, Mehto M \& Janne OA 1994 Analysis of androgen receptor-DNA interactions with receptor proteins produced in insect cells. Fournal of Biological Chemistry 269 11514-11522.

Kallio PJ, Palvimo JJ \& Janne OA 1996 Genetic regulation of androgen action. Prostate Supplement 6 45-51.

Kasper S, Rennie PS, Bruchovsky N, Sheppard PC, Cheng H, Lin L, Shiu RPC, Snoek R \& Matusik RJ 1994 Cooperative binding of androgen receptors to two DNA sequences is required for androgen induction of the probasin gene. Fournal of Biological Chemistry 269 31763-31769.

Konig H, Ponta H, Rahmsdorf HJ \& Herrlich P 1992 Interference between pathway-specific transcription factors: glucocorticoids antagonize phorbol ester-induced AP-1 activity without altering AP-1 site occupation in vivo. EMBO Fournal 11 2241-2246.

Leidig F, Shepard AR, Zhang W, Stelter A, Cattini PA, Baxter JD \& Eberhardt NL 1992 Thyroid hormone responsiveness in human growth hormone-related genes: possible correlations with receptor-induced DNA conformational changes. Fournal of Biological Chemistry 267 913-921.

Lue NF, Buchman AR \& Kornberg RD 1989 Activation of yeast RNA polymerase II transcription by a thymidine-rich upstream element in vitro. Proceedings of the National Academy of Sciences of the USA 86 486-490.

Matusik RJ, Cattini PA, Leco KJ, Sheppard PC, Nickel BE, Neubauer BL, Davie JR, Chang C, Liao S, Matuo Y \& McKeehan WL 1991 Regulation of gene expression in the prostate. In Molecular and Cellular Biology of Prostate Cancer, pp 299-314. Eds JP Karr, DS Coffey, RG Smith \& DJ Tindall. New York and London: Plenum Press.

Miesfeld R, Rusconi S, Godowski PJ, Maler BA, Okret S, Wikstrom AC, Gustafsson JA \& Yamamoto KR 1986 Genetic complementation of a glucocorticoid receptor deficiency by expression of cloned receptor cDNA. Cell 46 389-399.

Nachtigal MW, Nickel BE, Klassen ME, Zhang W, Eberhardt NL \& Cattini PA 1989 Human chorionic somatomammotropin and growth hormone gene expression in rat pituitary tumour cells is dependent on proximal promoter sequences. Nucleic Acids Research 17 4327-4337. 
Nardulli AM, Greene GL \& Shapiro DJ 1993 Human estrogen receptor bound to an estrogen response element bends DNA Molecular Endocrinology 7 331-340.

Pearce D \& Yamamoto KR 1993 Mineralocorticoid and glucocorticoid receptor activities distinguished by nonreceptor factors at a composite response element. Science 259 1161-1165.

Rennie PS, Bruchovsky N, Leco KJ, Sheppard PC, McQueen SA, Cheng H, Block ME, MacDonald BS, Nickel BE, Chang C, Liao S, Cattini PA \& Matusik RJ 1993 Characterization of two cis-acting elements involved in the androgen regulation of the probasin gene. Molecular Endocrinology 7 23-36.

Riegman PH, Vlietstra RJ, van der Korput JA, Brinkmann AO \& Trapman J 1991 The promoter of the prostate-specific antigen gene contains a functional androgen responsive element. Molecular Endocrinology 5 1921-1930.

Roche PJ, Hoare SA \& Parker MG 1992 A consensus DNAbinding site for the androgen receptor. Molecular Endocrinology 6 2229-2235.

Rojo F \& Salas M 1991 A DNA curvature can substitute phage phi 29 regulatory protein $\mathrm{p} 4$ when acting as a transcriptional repressor. EMBO Fournal 10 3429-3438.

Rundlett SE \& Miesfeld RL 1995 Quantitative differences in androgen and glucocorticoid receptor DNA binding properties contribute to receptor-selective transcriptional regulation. Molecular and Cellular Endocrinology 109 $1-10$.

Schule R, Muller M, Kaltschmidt C \& Renkawitz R $1988 a$ Many transcription factors interact synergistically with steroid receptors. Science 242 1418-1420.

Schule R, Muller M, Otsuka Murakami H \& Renkawitz R $1988 b$ Cooperativity of the glucocorticoid receptor and the CACCC-box binding factor. Nature 332 87-90.

Schule R, Rangarajan P, Kliewer S, Ransone LJ, Bolado J, Yang N, Verma IM \& Evans RM 1990 Functional antagonism between oncoprotein c-Jun and the glucocorticoid receptor. Cell 62 1217-1226.

Strahle U, Schmid W \& Schutz G 1988 Synergistic action of the glucocorticoid receptor with transcription factors. EMBO Fournal 7 3389-3395.

Strahle U, Boshart M, Klock G, Stewart F \& Schutz G 1989 Glucocorticoid- and progesterone-specific effects are determined by differential expression of the respective hormone receptors. Nature 339 629-632.

Truss M \& Beato M 1993 Steroid hormone receptors: interaction with deoxyribonucleic acid and transcription factors. Endocrine Reviews 14 459-479.

Tsai SY, Carlstedt-Duke J, Weigel NL, Dahlman K, Gustafsson JA, Tsai MJ \& O’Malley BW 1988 Molecular interactions of steroid hormone receptor with its enhancer element: evidence for receptor dimer formation. Cell $\mathbf{5 5}$ 361-369.

Tsai SY, Tsai MJ \& O’Malley BW 1989 Cooperative binding of steroid hormone receptors contributes to transcriptional synergism at target enhancer elements. Cell 57 443-448.

Urness LD \& Thummel CS 1990 Molecular interactions within the ecdysone regulatory hierarchy: DNA binding properties of the Drosophila ecdysone-inducible E74A protein. Cell 63 47-61.

Yan Y, Sheppard PC, Kasper S, Lin L, Hoare S, Kapoor A, Dodd JG, Duckworth ML \& Matusik RJ 1997 A large fragment of the probasin promoter targets high levels of transgene expression to the prostate of transgenic mice. The Prostate 32 129-139.

Yang-Yen HF, Chambard JC, Sun YL, Smeal T, Schmidt TJ, Drouin J \& Karin M 1990 Transcriptional interference between c-Jun and the glucocorticoid receptor: mutual inhibition of DNA binding due to direct protein-protein interaction. Cell 62 1205-1215.

RECEIVED 21 September 1998 